\title{
Prescription Errors Still a Challenge in Pakistan - A Cross-Sectional Study from Central Punjab, Pakistan
}

\author{
Hafiz Obaid ${ }^{1}$, Ahmed Umer Sohaib ${ }^{1}$, Abu Bakar Munir ${ }^{1}$, Jamshaid Akbar ${ }^{1, *}$, Muhammad Qamar-uz-

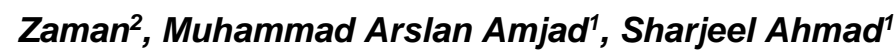

${ }^{1}$ Department of Pharmaceutical Sciences, The Superior College, Lahore, Pakistan

${ }^{2}$ Department of Pharmacy, The Islamia University of Bahawalpur, Bahawalpur, Pakistan

\author{
Authors' Contributions \\ 1,7 Conception \& Study Design, Data \\ Collection, Data Analysis. \\ 2 Conception \& Study Design, Drafting. \\ 3 Critical Review. \\ 4 Data Analysis, Drafting. \\ 5 Drafting, Critical Review. \\ 6 Conception \& Study Design, Data Collection.
}

\section{Article info.}

Received: December 4, 2019

Accepted: January 20, 2020

Funding Source: Nil

Conflict of Interest: Nil

Cite this article: Obaid $\mathrm{H}$, Sohaib $A U$, Munir

AB, Akbar J, Qamar-uz-zaman M, Amjad MA,

Ahmad S. Prescription Errors Still a Challenge

in Pakistan - A Cross-Sectional Study from

Central Punjab, Pakistan. RADS J Pharm

Pharm Sci. 2019; 7(4): 181-185.

*Address of Correspondence Author:

dr.jamshaidsheikh@gmail.com

\section{A B S TRACT}

Objective: To evaluate the prescription writing pattern and errors in prescriptions at different health care units of Central Punjab, Pakistan.

Methods: A descriptive cross-sectional study design was adopted to conduct the present study. Data collection was done for a period of one month i.e. March 2018 from selected community pharmacies of five different cities of Central Punjab, Pakistan. Patients were approached irrespective of age and gender and data was recorded on a pre-designed Performa. The total sample size was 750 (150 prescriptions from each pharmacy). SPSS (Statistical Program for Social Sciences, version 20.0) was used for statistical analysis of data.

Results: Out of 750 prescriptions, 662 prescriptions were included in final analysis. Patient name was found written in almost all prescriptions 660 (99.7\%) while physician name was missing on 519 (78.4\%). Healthcare provider registration number and qualification were not on 654 (98.8\%) and $527(79.6 \%)$ prescriptions respectively. Poly-pharmacy was observed in 103 (16\%) prescriptions and no prescription was found with generic name.

Conclusion: The study results highlighted the imperative need to devise policies that should be regulated and implemented by the healthcare authorities to make our prescriptions in line with the prescribed guidelines.

Keywords: Prescription errors, rational prescribing, poly-pharmacy, Central Punjab.

\section{INTRODUCTION}

Prescription writing is the only practice that conveys therapeutic message from physician to the patient via pharmacist. A prescription has different parts each with its own significance that cannot be ignored. These parts include superscription, inscription, subscription and the signa or Signatura [1]. A prescription should be adherent to the prescription writing guidelines which is extremely important for the safety and benefit of the patients [2].
Since prescription writing is one of the common task performed in daily general practice, there seems an abundant evidence of continuous poor prescriptions writing practice worldwide [3]. This poor practice majorly results in various Medication Errors (MEs), Adverse Drug Events (ADEs), potential Drug Interactions (DI) that ultimately leads to treatment prolongation, patient distress and also increases the medication and treatment cost [4-6]. It is reported from a study that errors in prescriptions account for $70 \%$ of medication errors that could potentially develop adverse effects [7]. MEs take place at five different levels which are disease diagnosis, 
prescription writing, dispensing, routes of administration and drug therapeutic monitoring [8].

There are various factors that accounts for prescription errors among which communication gap between physician and patient, taking incomplete patient history, transcription error and ignoring patient clinical picture while writing prescription are listed on the top [9]. Due to huge number of patients, the physician aims to spend no more than 5 minutes for diagnosis that keeps the practitioner unaware of patient previous history and also about the patient's health status [10]. It has also been observed that normally many healthcare providers are adopting the concept of poly-pharmacy leading to irrational prescribing and a sharp climb towards the cost of the medication as well.

Irrational prescribing is observed globally but due to insufficient funds and resources, it is more common and increasing constantly in the developing countries [11]. The one way to promote rational prescribing and avoid prescription errors is to quantify it. World Health Organization (WHO) in collaboration with international network for rational use of drugs have devised indicators to evaluate and quantify prescription for rationality [12, 13]. Moreover, guidance on prescription writing is also available in various reference handbooks i.e. the British National Formulary (BNF).

In Pakistan, unfortunately the legal check and balance on prescriptions is not up to the mark and that stands as a major factor contributing in poor prescribing practice. So, the current study was undertaken with an aim to evaluate the prescription errors and prescribing pattern at different health care facilities in Central Punjab, Pakistan.

\section{MATERIALS AND METHODS}

A descriptive cross-sectional study design was applied to conduct the present study. Data was gathered by collecting prescriptions and recording data on a well-designed Performa for a period of one month, March 2018 from selected community pharmacies of five different cities of Central Punjab, Pakistan. Pharmacies for data collection were selected based on the patient flow/average number of patients visiting pharmacy per day and those which were in vicinity of two or more public or private healthcare centers (hospitals, clinics, etc.). All patients who visited the pharmacy were approached randomly irrespective of gender and age and invited to participate in the study and only those who showed consent to participate were included in the study. All those patients who visited pharmacy second time with the same prescription were excluded from the study.

The total sample size was 750 (150 prescriptions collected from each pharmacy) out of which 662 prescriptions were considered for final evaluation based on set inclusion criteria. Each prescription was evaluated according to prescription writing guidelines available in British National Formulary (BNF) and World Health Organization (WHO) whilst statistical analysis was done by using SPSS (Statistical Program for Social Sciences, version 20.0). Descriptive statistics were applied to evaluate the results.

\section{RESULTS}

Out of 662 prescriptions almost all prescriptions 660 $(99.7 \%)$ contained healthcare unit name. The prescriber name was present on $143(21.6 \%)$ while the qualification of the practitioner to identify the area of practice was present only on 135 (20.4\%) prescriptions. The government had issued a registration number to practitioners and only $8(1.2 \%)$ prescriptions were mentioned with this information while the clinic information regarding the address of clinic or health care unit was found on 659 (99.5\%) prescriptions. Health care unit or clinic contact number was mentioned on 169 (25.5\%) prescription while $493(74.5 \%)$ lacked this information. The date of prescription was found on majority 661 (99.8\%) prescriptions (Table 1).

Table 1. Analysis of healthcare facility \& prescriber information on prescriptions $(n=662)$.

\begin{tabular}{|c|c|c|}
\hline \multirow{2}{*}{$\begin{array}{c}\text { Prescription } \\
\text { Elements }\end{array}$} & $\begin{array}{c}\text { Yes } \\
\text { N (\%) }\end{array}$ & $\begin{array}{c}\text { No } \\
\text { N (\%) }\end{array}$ \\
\cline { 2 - 3 } & $660(99.7)$ & $2(0.3)$ \\
\hline $\begin{array}{c}\text { Health Care } \\
\text { Unit name }\end{array}$ & $143(21.6)$ & $519(78.4)$ \\
\hline Name & $135(20.4)$ & $527(79.6)$ \\
\hline Qualification & $8(1.2)$ & $654(98.8)$ \\
\hline $\begin{array}{c}\text { Registration } \\
\text { Number }\end{array}$ & $659(99.5)$ & $3(0.5)$ \\
\hline Clinic Address & $169(25.5)$ & $493(74.5)$ \\
\hline $\begin{array}{c}\text { Clinic Contact } \\
\text { Number }\end{array}$ & $661(99.8)$ & $1(0.2)$ \\
\hline $\begin{array}{c}\text { Date of } \\
\text { Prescription }\end{array}$ & \\
\hline
\end{tabular}


Out of total 662 prescriptions, $660 \quad(99.7 \%)$ prescriptions contain patient's name. About 544 $(82.2 \%)$ and 453 (68.4\%) prescriptions had mentioned patient age and sex respectively. The patient weight that is necessary for deciding dose was missed on $98.9 \%$ prescriptions. And interestingly no prescription contained patient address that has to be mentioned on prescription (Table 2).

Table 2. Analysis of patient demographics on prescriptions $(n=662)$.

\begin{tabular}{|l|c|c|}
\hline \multirow{2}{*}{$\begin{array}{c}\text { Prescription } \\
\text { Elements }\end{array}$} & \multicolumn{2}{|c|}{ Response } \\
\cline { 2 - 3 } & $\begin{array}{c}\text { Yes } \\
\text { N (\%) }\end{array}$ & $\begin{array}{c}\text { No } \\
\text { N (\%) }\end{array}$ \\
\hline Patient Name & $660(99.7)$ & $2(0.3)$ \\
\hline Patient Age & $544(82.2)$ & $118(17.8)$ \\
\hline Patient Sex & $453(68.4)$ & $209(31.6)$ \\
\hline Patient Weight & $7(1.1)$ & $655(98.9)$ \\
\hline $\begin{array}{l}\text { Patient } \\
\text { Address }\end{array}$ & $0(0.0)$ & $662(100)$ \\
\hline
\end{tabular}

Evaluation of necessary parts of prescription showed that all $662(100 \%)$ prescriptions were with the inscription part. Major number of the prescriptions 618 $(93.3 \%)$ were with the directions to the pharmacist whereas $54(8.1 \%)$ prescriptions were without the directions to patient. Moreover, majority of the prescriptions 605 (91.4\%) were with the signatures of a prescriber. The results found in our study related to generic prescription were worst, as not even a single prescription found with generic names of drugs (Figure 1).

Prescriptions with five or more than five drugs were considered poly-pharmacy. It was observed in 559 (84\%) prescriptions and $103(16 \%)$ were without it (Figure 2).

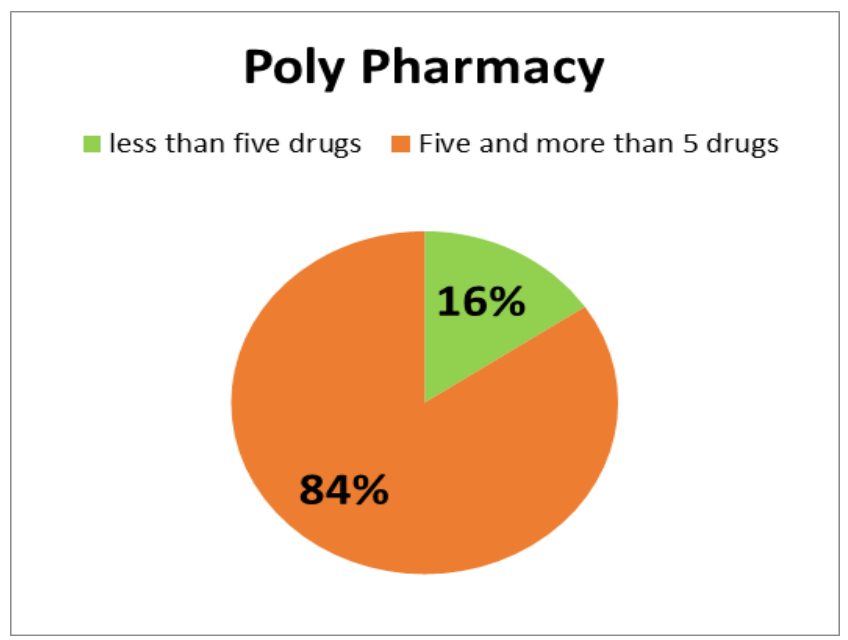

Figure 2. Evaluation of poly-pharmacy.

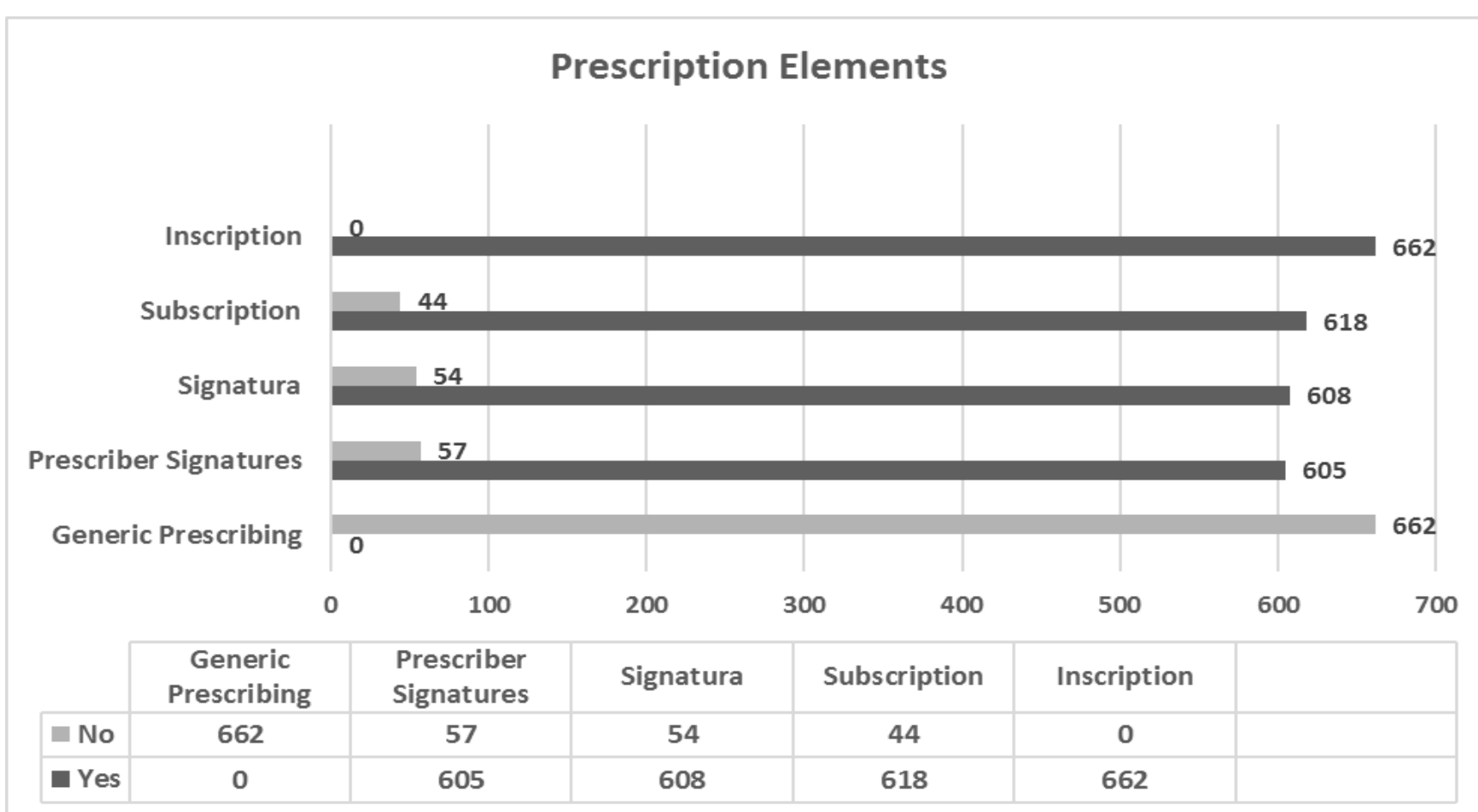

Figure 1. Evaluation of main parts of prescription. 


\section{DISCUSSION}

To our best knowledge, the current study is among the very few studies that determines the prevalence and prescription errors in Central Punjab, Pakistan. Present study results demonstrated that most of the prescriptions $(79.6 \%)$ didn't contain physician qualification that specifies the specialization or area of practice of physician and the results were comparable to the study conducted in Palestine [14].

Date of prescription was mentioned in almost all prescriptions, and in a few prescriptions (17.8\%) patient age was not mentioned, whereas this practice was poorly followed in Saudi Arabia where most prescriptions $(25.7 \%)$ were found without date and almost same results were seen in patient's age. This can be misleading, particularly for children dosage regimen and elderly with poor body functions. The reason for this poor practice in Saudi Arabia was the lack of provision of knowledge about prescription parts in their studies. Another investigation that evaluated medical students performance in a prescription writing exercise suggested that the root cause of prescription errors was lack of relevant knowledge of prescription writing guidelines [15]. To ensure and promote the safe and effective prescription practice the clinical section of the British Pharmacological Society developed a curriculum that includes the guidelines for teaching safe and standard prescription protocols [16].

Regarding patient information, our finding showed that prescriptions were deficient in patient's name, age and sex in $0.3 \%, 17.8 \%$ and $31.6 \%$ of prescriptions, respectively. This information resembled with the results of a similar study [17]. A study from Oman reveals high percentage of errors related to patient profile. No patient prescription was found having a medical record number mentioned on it. The reason is that the physicians usually keep all records in patient medication file that can be retrieved during the follow up visits [18].

Patient's body weight was not stated in (98.9\%) prescriptions which may lead to severe medication errors of overdosing as most of the patients particularly those with age less than 12 years needs calculated dose based on body weight. Similar results were reported in studies conducted in different cities of Pakistan. The patient's height and weight must be part of prescription because these elements are important in calculating renal creatinine clearance for renal dose adjustment for patients on dialysis or impaired renal function [19].

Prescriber's signature is important as it authenticates the prescription and without it, the drug cannot be compounded and dispensed to the patient. The percentage of this error in current study was $8.6 \%$ which was slightly higher as compared to previous reported studies [20]. Furthermore, our study showed $6.64 \%$ errors in case of subscription as compared to the study conducted in Oman which demonstrated $46.33 \%$ of prescriptions that had incomplete direction to pharmacist for patient (subscription), which could lead to misunderstanding. For instance, some drugs should only be taken at night while some combinations of drugs cannot be taken together due to potential ADRs and drug interactions. Directions should be clear, complete, and should provide careful instructions to the pharmacist for the patient [18].

A number of studies suggested the implementation of computer based system for prescribing the drugs. Similar studies conducted in Boston showed that it is possible to reduce the medication and prescription errors by using computer based system of prescription medications [21].

The findings can enable the pharmacists to better understand the severity and nature of prescription errors in Central Punjab, Pakistan and therefore to develop strategies to reduce such errors.

\section{CONCLUSION}

The prescription writing practice was not very much satisfactory. Lack of healthcare center addresses, prescriber's information and patient information were the issues highlighted in the prescriptions. We recommend larger and more comprehensive surveys at regular intervals and dissemination of these ground realties to policy makers to devise such policies and plans to overcome the prescription errors.

\section{ACKNOWLEDGEMENTS}

The author would like to pay thanks to all respondents and staff members of the community pharmacy who participated and helped us in this study. 


\section{REFERENCES}

1. Goodman LS. Goodman and Gilman's the pharmacological basis of therapeutics: McGrawHill New York; 1996.

2. De Vries T, Henning R, Hogerzeil HV, Fresle D, Policy M, Organization WH. Guide to Good Prescribing: A Practical Manual. 1994.

3. Aronson JK. A prescription for better prescribing. Br J Clin Pharmacol. 2006; 61(5):487-91.

4. Rathish D, Bahini S, Sivakumar T, Thiranagama T, Abarajithan T, Wijerathne B, et al. Drug utilization, prescription errors and potential drug-drug interactions: an experience in rural Sri Lanka. BMC Pharmacol Toxicol. 2016; 17(1):27.

5. Aronson JK. Medication errors: what they are, how they happen, and how to avoid them. QJM. 2009; 102(8):513-21.

6. Akbar J, Munir AB, Qamar-uz-Zaman M, Masood I, Jabbar Z, Amjad MA. Potential Drug-Drug Interactions; A Study Among Patients of Intensive Care Unit (ICU) of a Tertiary Care Hospital of South Punjab, Pakistan. RADS J Pharm Pharm Sci. 2019; 7(2):78-83.

7. Velo GP, Minuz P. Medication errors: prescribing faults and prescription errors. Br J Clin Pharmacol. 2009; 67(6):624-8.

8. Chaudhari V, Chaudhari B, Khairnar A. A crosssectional prescription audit database for antianginal drugs with impact of essential drug list and standard treatment guidelines on prescription pattern in Nasik city. Res J Pharm Technol. 2011; 4:1111-4.

9. Dean B, Schachter M, Vincent C, Barber N. Prescribing errors in hospital inpatients: their incidence and clinical significance. Qual Saf Health Care. 2002; 11(4):340-4.

10. Shera AS, Jawad F, Basit A. Diabetes related knowledge, attitude, and practices of family physicians in Pakistan. J Pak Med Assoc. 2002; 52(10):465-70.

11. Sudheer G, Srinivasan K, Prabhu GR. A study of prescription writing practices of doctors in medical units in a teaching hospital. J NTR Univ Health Sci. 2013; 2(1):22-4.

12. De Vries $T$, Henning $R H$, Hogerzeil HV, Fresle D, Policy M, Organization WH. Guide to good prescribing: a practical manual. Geneva: World Health Organization, 1994.

13. Organization WH. How to investigate drug use in health facilities: selected drug use indicators. Geneva: World Health Organization, 1993.

14. Sawalha AF, Sweileh WM, Zyoud SH, Al-Jabi SW, Shamseh FF, Odah A. Analysis of prescriptions dispensed at community pharmacies in Nablus, Palestine. East Mediterr Health J. 2010; 16(7):788-92.

15. Boreham NC, Mawer GE, Foster RW. Medical students' errors in pharmacotherapeutics. Med Educ. 2000; 34(3):188-93.

16. Maxwell S, Walley $\mathrm{T}$. Teaching safe and effective prescribing in UK medical schools: a core curriculum for tomorrow's doctors. $\mathrm{Br} \mathrm{J}$ Clin Pharmacol. 2003; 55(6):496-503.

17. Balbaid OM, Al-Dawood KM. Assessment of physician's prescribing practices at Ministry of Health Hospitals in Jeddah City-Saudi Arabia. Saudi Med J. 1998; 19(1):28-31.

18. Al Shahaibi NM, Al Said LS, Kini TG, Chitme HR. Identifying errors in handwritten outpatient prescriptions in Oman. J Young Pharm. 2012; 4(4):267-72.

19. Saleem R, Dayo A, Ghoto MA, Akram M, Arain MI, Ali A. Prescription writing error in general practice: A cross sectional study at tertiary care hospital in Hyderabad, Pakistan. IOSR J Pharm Biol Sci. (IOSR-JPBS). 2013; 8(4):72-7.

20. Shah SN, Aslam M, Avery AJ. A survey of prescription errors in general practice. Pharm J. 2001; 267(7178):860-2.

21. Bates DW, Leape LL, Cullen DJ, Laird N, Petersen LA, Teich JM, et al. Effect of computerized physician order entry and a team intervention on prevention of serious medication errors. JAMA. 1998; 280(15):1311-6.

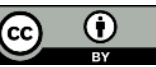

This is an Open Access article distributed under the terms of the Creative Commons Attribution License (http://creativecommons.org/licenses/by/4.0), which permits unrestricted use, distribution, and reproduction in any medium, provided the original work is properly cited. 